\title{
Exploring Infection of Wheat and Carbohydrate Metabolism in Mycosphaerella graminicola Transformants with Differentially Regulated Green Fluorescent Protein Expression
}

\author{
Eric A. Rohel, ${ }^{1}$ Andrew C. Payne, ${ }^{2}$ Bart A. Fraaije, ${ }^{2}$ and Derek W. Hollomon ${ }^{2}$ \\ ${ }^{1}$ INRA Centre de Recherches Agronomiques de Rennes, UMR BiO3P, Domaine de la Motte, B.P. 35327, \\ 35653 Le Rheu Cedex, France; 'IACR-Long Ashton Research Station, Department of Agricultural \\ Sciences, University of Bristol, Long Ashton, BS41 9AF Bristol, U.K. \\ Accepted 12 September 2000.
}

\begin{abstract}
A Mycosphaerella graminicola strain transformed with the green fluorescent protein (GFP) downstream of either a carbon source-repressed promoter or a constitutive promoter was used to investigate in situ carbohydrate uptake during penetration of the fungus in wheat leaves. The promoter region of the acu-3 gene from Neurospora crassa encoding isocitrate lyase was used as a carbon sourcerepressed promoter. The promoter region of the Aspergillus nidulans gpdA gene encoding glyceraldehyde-3phosphate dehydrogenase was used as a constitutive promoter. Fluorometric measurement of GFP gene expression in liquid cultures of $a c u-3$-regulated transformants indicated that the $N$. crassa acu-3 promoter functions in $M$. graminicola as it does in $N$. crassa, i.e., acetate induced and carbon source repressed. Glucose, fructose, and saccharose triggered the repression, whereas mannitol, $x y-$ lose, and cell wall polysaccharides did not. Monitoring the GFP level during fungal infection of wheat leaves revealed that $a c u-3$ promoter repression occurred after penetration until sporulation, when newly differentiated pycnidiospores fluoresced. The use of GFP transformants also allowed clear visualization of $M$. graminicola pathogenesis. No appressoria were formed, but penetration at cell junctions was observed. These results give new insight into the biotrophic status of M. graminicola.
\end{abstract}

Additional keywords: plant-pathogenic fungus, septoria blotch, Septoria tritici, UB7.

Nutrient transfer between a biotrophic pathogen and its host is fundamental to the outcome of infection. Although specialized feeding structures such as haustoria can be differentiated during leaf colonization, there is a possibility that nutrient

Corresponding author: E. Rohel; E-mail: rohel@ rennes.inra.fr

Current address of A. C. Payne: Prolifix Ltd., 91 Milton Park, Abingdon, Oxon OX14 4RY, U.K.

Current address of B. A. Fraaije: IACR-Rothamsted Experimental Station, Department of Plant Pathology, Harpenden, Hertfordshire, AL5 2JQ, U.K. transfer initiates much earlier during the penetration process and plays a part in the recognition compatibility of the hostpathogen interaction.

Mycosphaerella graminicola (anamorph Septoria tritici), the causal agent of Septoria blotch of wheat, is a hemibiotroph (Parbery 1996). Penetration through stomata occurs within 12 to $48 \mathrm{~h}$ after inoculation (Kema et al. 1996). After penetration, the fungus behaves as a symptomless endophyte. Hyphae colonize intercellular spaces without causing cell death for a period of 3 to 5 weeks before necrosis and sporulation occur (Royle et al. 1986). Hyphae are strictly ectotrophic, and no haustoria are formed. Kema et al. (1996) reported differences between a compatible and resistant interaction $48 \mathrm{~h}$ or more after inoculation, with mesophyll cell ultrastructure being affected and colonization taking place only in the susceptible cultivar. This suggests establishment of an interface with the host at the beginning of infection through which various substances, including nutrients, can pass.

Until now, few data were available on the development of such an interface. In ectotrophic fungi, nutrient transfer is thought to involve specialized intercellular hyphae (Hardham 1992), described by Heath and Skalamera (1997) as "conspicuously wider than those growing nonbiotrophically in the same plant." Evidence for fungal structure-dependent nutrient uptake has been obtained from pulse-chase experiments carried out with ${ }^{14} \mathrm{CO}_{2}$ (Clark and Spencer-Phillips 1993; Manners and Gay 1982). Results obtained by this method, however, give only a fragmented picture of the time course of nutrient transfer during infection, which cannot be related confidently to fungal structures localized inside the host.

We used an $M$. graminicola strain transformed with either a carbon source-repressed promoter-green fluorescent protein (GFP) fusion or a constitutive promoter-GFP fusion construct in order to investigate in situ soluble carbohydrate uptake during infection. Expression of the S65T GFP variant (Sheen et al. 1995) under the control of various promoters has been reported in several fungal plant pathogens (Maor et al. 1998; Spellig et al. 1996). Recently, GFP has been used successfully to monitor gene expression during the Ustilago maydis infection cycle (Basse et al. 2000). The promoter region of the $\mathrm{acu}$ 3 gene from Neurospora crassa encoding isocitrate lyase (EC 
4.1.3.1) was used as an inducible promoter. Isocitrate lyase is a key enzyme of the glyoxylate cycle that cleaves isocitrate to glyoxylate and succinate, and its synthesis has been shown to be carbon source repressed and acetate induced in $N$. crassa (Bibbins et al. 1998). The promoter region of the Aspergillus nidulans gpdA gene encoding glyceraldehyde-3-phosphate dehydrogenase (EC 1.2.1.12) was used as a constitutive promoter (Kershaw et al. 1998; Punt et al. 1990). Both $a c u-3$ and gpdA promoter regulation were shown to be conserved in $M$. graminicola and readily allowed the detection of wheatsoluble carbohydrate uptake by the fungus after penetration.

\section{RESULTS}

\section{Fluorometric monitoring of GFP synthesis} in spore suspensions.

In acu-3-regulated $M$. graminicola transformants, GFP synthesis was strongly induced by acetate and repressed by glucose (Fig. 1). Increasing glucose concentration from 50 to $250 \mathrm{mM}$ resulted in stronger repression. Among other carbohydrates tested, fructose (Fig. 1), galactose, maltose, and saccharose (Fig. 2) triggered the repression, though to a lesser extent than glucose. Xylose, fungal metabolite mannitol (Fig. 2 ), and the structural polysaccharides cellobiose, dextran, and arabinogalactan all failed to repress $a c u$-3-regulated GFP synthesis. Acetate was the strongest inducer of the $a c u-3$ promoter activity that we tested. Citrate had no effect, and tartrate induced GFP synthesis in both $a c u$-3- and gpdA-regulated transformants (Fig. 2). In gpdA-regulated transformants, GFP expression was not significantly repressed as a function of the carbon source. All $a c u$-3- and gpdA-regulated transformants tested (at least two per construct and carbon source) behaved consistently with the above findings, despite showing different morphologies and levels of fluorescence. The background fluorescence of untransformed strain ST16 was negligible in our assays (less than 5\% of GPD-GFP6 transformant fluorescence in water or carbohydrate media under standard settings used for fluorometric measurements).

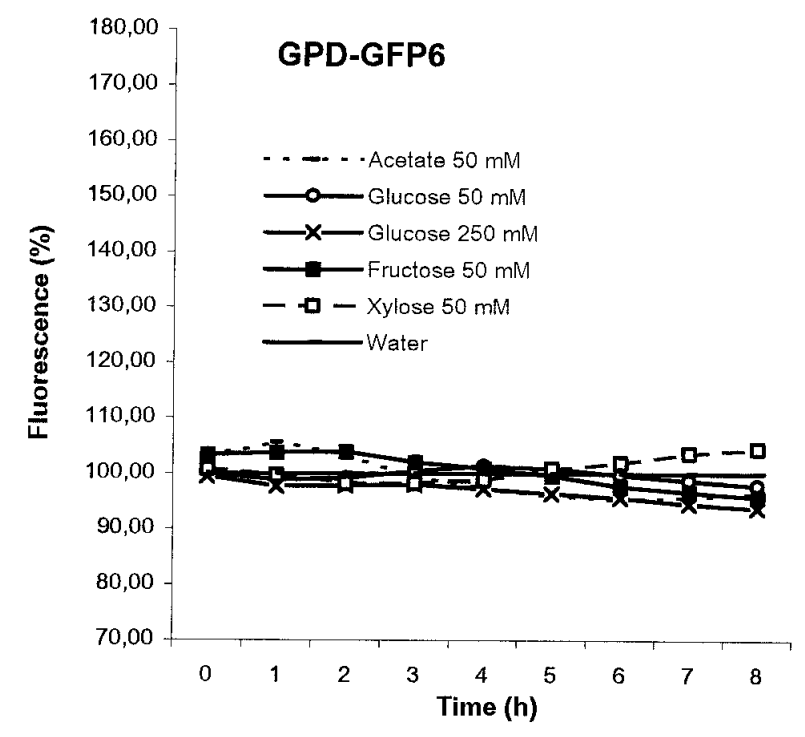

Western blot and polymerase chain reaction (PCR) analysis of infected wheat leaves.

In carbon-starved media (Fig. 3), gpdA-regulated GPDGFP6 transformant and $a c u$-3-regulated ICL-GFP45 transformant expressed similar levels of GFP as detected by an antiGFP antibody in Western blots. In infected leaves (Fig. 4),

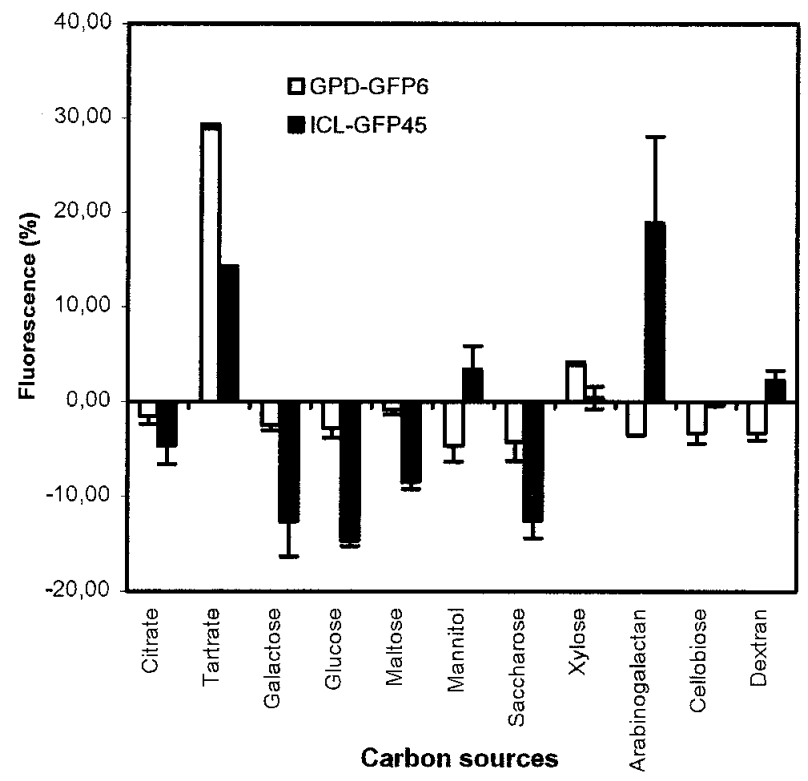

Fig. 2. Fluorometric measurement of green fluorescent protein (GFP) gene expression in response to a 10 -h incubation with different carbon sources in starved liquid cultures of gpdA-regulated GPD-GFP6 and acu-3-regulated ICL-GFP45 transformants. Fluorescence is expressed as a percentage of the transformant fluorescence in water. Carbon sources were added at a final concentration of $50 \mathrm{mM}$ at time 0 . We ensured that the fluorescence measured after $10 \mathrm{~h}$ was the result of a steady increase or decrease of fluorescence over the incubation period. The average and standard error of two measurements were taken from separate assays.

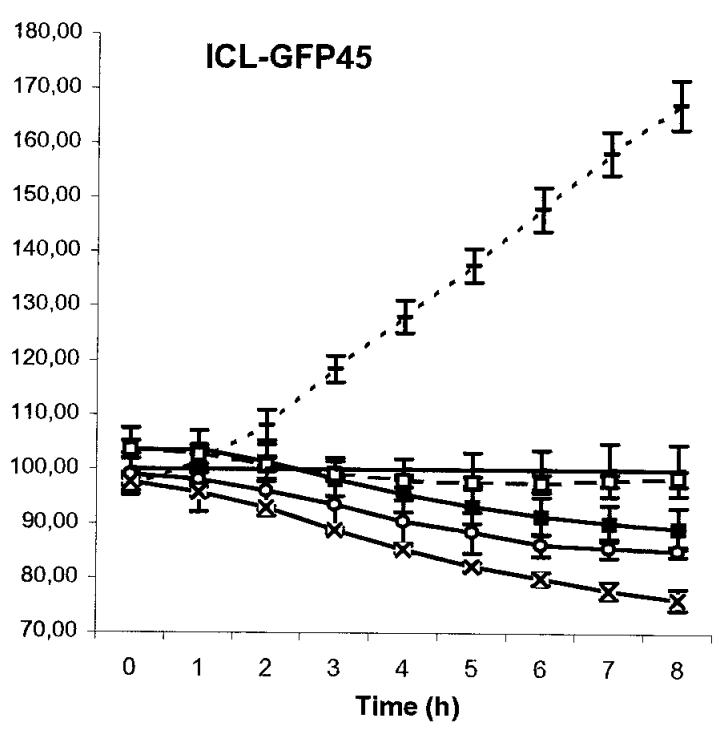

Fig. 1. Time course fluorometric measurement of green fluorescent protein (GFP) gene expression in response to carbon source in starved liquid cultures of gpdA-regulated GPD-GFP6 and $a c u$-3-regulated ICL-GFP45 transformants. Fluorescence is expressed as percentage of transformant fluorescence in water. Carbon sources were added at indicated final concentrations at time 0 . The average and standard error of two measurements were taken from separate assays. 
GFP (approximately $30 \mathrm{kDa}$ ) (Fig. 4C) was detected by Western blotting in $g p d A$ - or $a c u$-3-regulated transformants 1 day postinoculation (dpi) (prior to penetration). At 9 dpi (after penetration), GFP was detected in leaves infected by gpdAbut not $a c u$-3-regulated transformants. Unlike GFP, the constitutively expressed fungal glycoprotein (approximately 60 kDa) (Fig. 4B), recognized by the antibody UB7 (Mitchell et al. 1997), was detected at 1 and 9 dpi in leaves infected by both types of $M$. graminicola transformants and in the wildtype strain ST16. Quantification of M. graminicola DNA in infected leaves by PCR (Fig. 4D) confirmed the progress of infection between 1 and 9 dpi for every transformant and ST16. Similar results were obtained with gpdA-regulated GPD-GFPB3 transformant and $a c u$-3-regulated ICL-GFP4 transformant in Western blot and PCR analysis, despite different intrinsic fluorescence levels. The presence of fungal penetrating structures in leaves was confirmed by fluorescence microscopy. Anti-GFP and UB7 antibodies gave no signal with healthy plant DNA (data not shown).

\section{Pathogenic development of GFP transformants in wheat leaves.}

gpdA- and acu-3-regulated GFP transformants infected wheat and produced mature pycnidia 3 weeks after inoculation in the same way as the wild type. Although inoculated spores adhered everywhere on the leaf, they were found more frequently in stomatal depressions (Fig. 5A and B) and wrapped around trichomes (Fig. 5C). Germ tubes often failed to penetrate the leaf. Penetration occurred within $24 \mathrm{~h}$ after inoculation. Penetrating structures were observed over stomata (Fig. 5B) at the anticlinal junction of epidermal cells (Fig. 5D) and at hair base cell junctions. No appressoria were formed. Confocal microscopy confirmed actual penetration of the fungus through stomata (Fig. 5E) and between host epidermal cells (Fig. 6). Once within the leaf, mycelial strands extended longitudinally following lower junctions of epidermal cells (Fig. 6) and wrapped around mesophyll cells (Fig. 5E and H). Despite extensive hyphal growth in the apoplast, host cell wall integrity was preserved up to 4 days before sporulation.

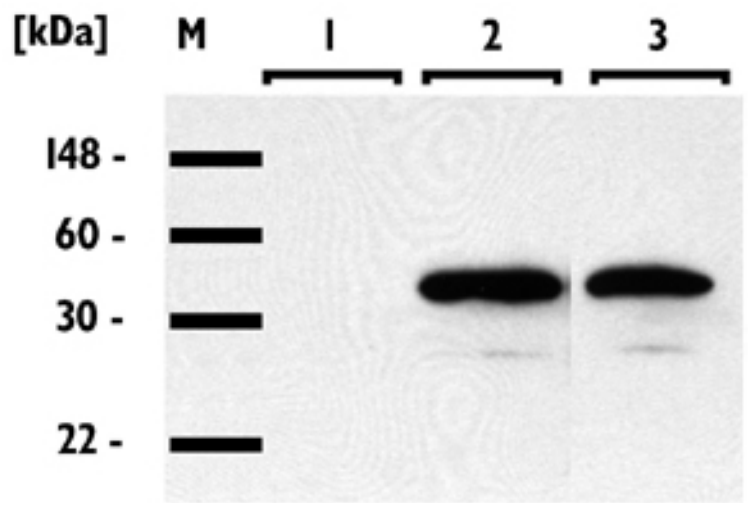

Fig. 3. Western blot analysis of green fluorescent protein (GFP) expression in starved liquid cultures of gpdA-regulated and $a c u$-3-regulated transformants. Lane 1: untransformed ST16 strain. Lane 2: gpdAregulated GPD-GFP6 transformant. Lane 3: acu-3-regulated ICL-GFP45 transformant. Lane M: molecular mass markers.
In planta fluorescence monitoring in gpdA- or acu-3regulated GFP transformants infection structures.

In the various stages prior to penetration, GFP fluorescence could be readily detected in $g p d A$ - and $a c u$-3-regulated trans-
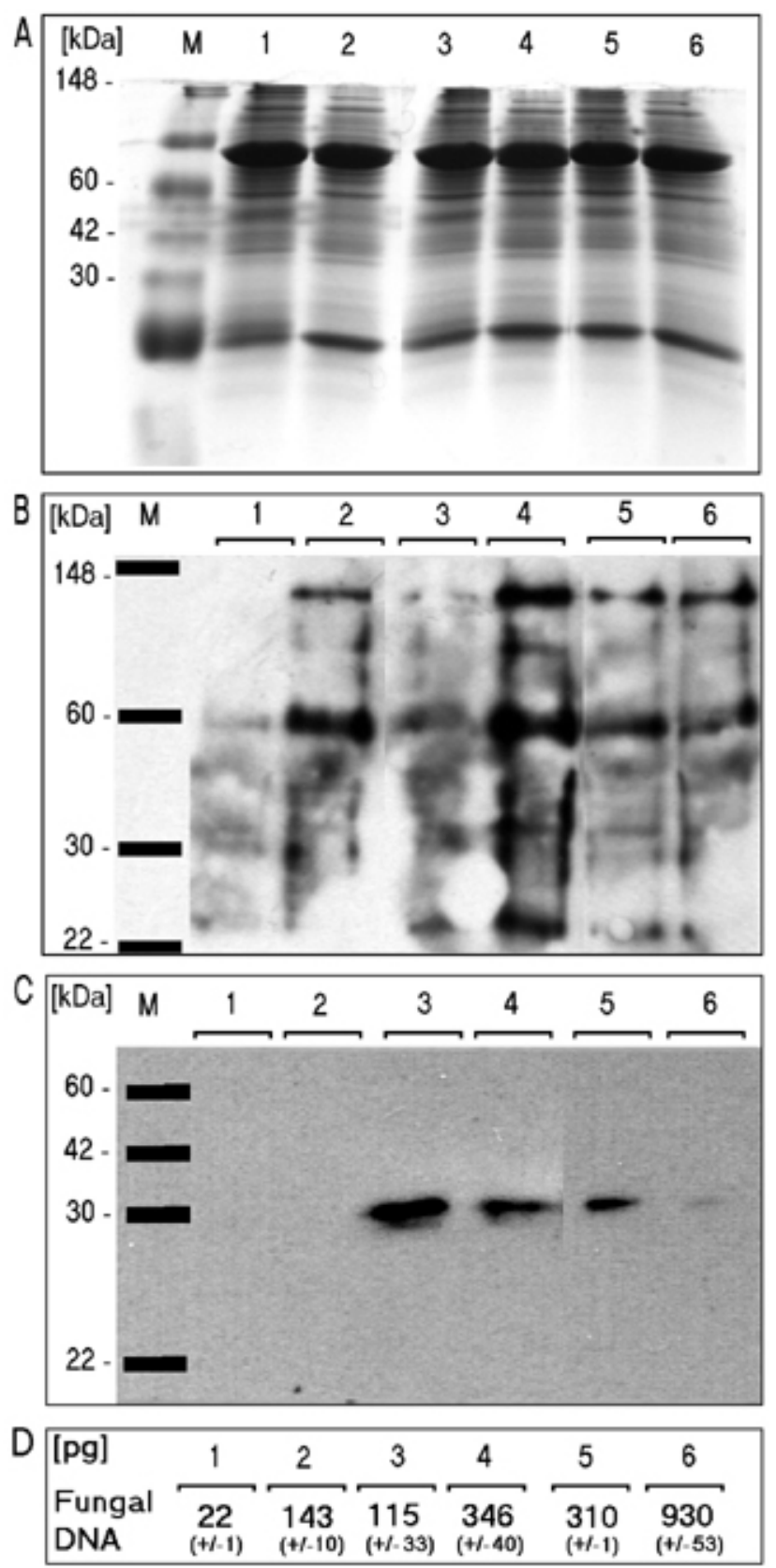

Fig. 4. Western blot analysis of green fluorescent protein (GFP) expression and polymerase chain reaction (PCR) quantification of fungal DNA in wheat leaves infected by $g p d A$ - and $a c u$-3-regulated transformants. Lanes 1 and 2: leaves infected by untransformed ST16 strain. Lanes 3 and 4: gpdA-regulated GPD-GFP6 transformant. Lanes 5 and 6: $a c u-3-$ regulated ICL-GFP45 transformant. Lanes 1, 3, and 5: leaves sampled at 1 day postinoculation (dpi). Lanes 2, 4, and 6: leaves sampled at 9 dpi. A, Coomassie-stained gel of total protein extracts. B, Western blot probed with fungal glycoprotein-specific monoclonal antibody UB7. C, Western blot probed with anti-GFP monoclonal antibody. D, PCR quantification of Mycosphaerella graminicola DNA (pg/100 ng of wheat DNA). Average and standard error of two measurements from separate PCR assays. Lane M: molecular mass markers. 
formants. Maximum fluorescence intensity was reached in penetrating structures, usually appearing as bright dots on the plant surface in all transformants. After penetration, GFP fluorescence was readily observed in intercellularly growing hyphae of gpdA-regulated transformants (Figs. 5E and $\mathrm{H}$ and 6). By contrast, $a c u-3$-regulated transformants stopped fluorescing immediately after penetration, whether in the substomatal chamber before reaching the mesophyll cells (Fig. 7) or after formation of a bright penetrating structure as in the case of penetration at a cell junction. No fluorescent $a c u$-3-regulated transformant hyphae could be detected in the mesophyll in leaf sections by confocal microscopy. Only when pycnidia were formed could the penetrated $a c u-3$-regulated transformants be detected again under UV because newly differentiated pycnidiospores were fluorescing (Fig. 5F and G).

\section{DISCUSSION}

Fluorometric measurement of GFP gene expression in response to carbon source in liquid cultures of $a c u$-3-regulated transformants indicated that the $N$. crassa acu-3 promoter functions in $M$. graminicola as it does in N. crassa, i.e., glucose repressed and acetate induced (Bibbins et al. 1998). Repression by fructose, galactose, and saccharose is consistent with $A$. nidulans isocitrate lyase gene $a c u D$ promoter regulation (Bowyer et al. 1994; McCullough and Roberts 1980). While McCullough and Roberts (1980) noticed partial derepression on glutamate or proline, the complete lack of repression on C6 carbohydrates such as xylose or mannitol was not reported by other authors. None of the cell wall polysaccharides tested repressed $a c u-3$ promoter activity in liquid cultures. Hence, in planta fluorescence changes in acu-3-regulated transformants most likely reflect uptake of predominantly metabolic sugars from the plant by the fungus throughout the infection process. The gpdA-regulated transformants provided a good control in detection techniques because they were not subject to carbon source repression in liquid cultures and, consequently, the GFP gene was expressed at all stages of the infection process.

Western blot analysis was consistent with microscopic assessment of GFP fluorescence during infection. GFP was detected prior to penetration (1 dpi) but not during internal growth (9 dpi) in acu-3-regulated transformants, whereas it was detected at both infection stages in gpdA-regulated transformants. Consistent with the work by Mitchell et al. (1997), UB7 bound specifically to infected plant material and detected the fungus at $9 \mathrm{dpi}$ in leaves infected with $a c u$-3-regulated transformants. Monitoring fungal DNA levels also confirmed that, at $9 \mathrm{dpi}$, infection was in progress in all leaf samples, including those inoculated with $\mathrm{acu}$-3-regulated transformants. Differences in DNA quantities measured between strains may be a result of a slight variation in spore size or adhesion properties because every sample was inoculated with the same spore concentration. The contribution of initial inoculum to detection at 9 dpi is likely to be reduced, considering the extensive degradation and removal of spores on the leaf surface observed at this stage in our assays.

During development on the leaf surface, GFP was strongly expressed in $a c u-3$ - and $g p d A$-regulated transformants. This is consistent with the fact that soluble carbohydrates are usually present on the leaf surface in very small quantities (nanograms per square centimeter) (Derridj 1996). GFP fluorescence in- creased in epicuticular penetration structures, possibly as a result of cytoplasm condensation, enhanced protein synthesis, or the presence of vertical hyphae in the leaf plane. Repression of GFP synthesis in acu-3-regulated (but not gpdAregulated) transformants was readily observed after penetration, indicating early carbohydrate uptake by penetrating hyphae. Penetration was always direct, without formation of an appressorium. Kema et al. (1996) used conventional light microscopy and scanning and transmission electron microscopy and did not observe penetration of the epidermis. In this study, confocal microscopy provided conclusive evidence that successful penetration between epidermal cells occurs, at least in some cultivar-isolate combinations. Hence, establishment of the host-pathogen interface does not seem to require the differentiation of specialized intercellular hyphae, at least at the beginning of the infection process. Soluble sugars are present in the apoplasm of graminaceous species at millimolar concentrations and are compatible with $a c u-3$ promoter repression (Tetlow and Farrar 1993). Interestingly, newly differentiated pycniospores were fluorescent in acu-3-regulated transformants, a result that gives new insight into the biotrophic status of M. graminicola. Parbery (1996) considered $M$. graminicola as a hemibiotroph, not a holobiotroph, because it seemed unlikely that a parasite would occupy a necrotic site rich in nutrients without utilizing them. The fluorescence of sporulating structures, however, suggests carbohydrate starvation at this stage in M. graminicola. Cohen and Eyal (1993) also reported that, in some cultivars, pycnidia on seedlings appear either prior to or without the formation of necrosis.

Although photosynthate uptake by epiphytic plant pathogens is well documented, there is little evidence available for endophytic fungi because an intimate host-pathogen association renders the examination of solute transport technically difficult. Clark and Spencer-Phillips (1993) reported on the assimilation of ${ }^{14} \mathrm{C}$-labeled pea apoplastic carbohydrates by intercellular hyphae of Peronospora viciae. Tetlow and Farrar (1993) found decreased apoplastic carbohydrate concentrations in barley leaves infected with the brown rust fungus Puccinia hordei and suggested that the uptake by intercellular hyphae was a possible cause of this reduction. There is indirect evidence for soluble carbohydrate uptake by the rice blast fungus Magnaporthe grisea in the report by Talbot et al. (1997). They found that the population of mRNAs expressed by the fungus during infection had a greater similarity with the mRNA population expressed during in vitro growth under nitrogen deprivation than under carbon deprivation. Coleman et al. (1997) suggested that several genes from fungal pathogens that exhibit in planta-induced expression are also starvation induced. However, their data suggest that starvation occurs quite late in the infection process (14 dpi) in Cladosporium fulvum. None of these methods related soluble carbohydrate uptake with differentiation of specific fungal structures, with the exception of haustoria in $P$. viciae.

The use of GFP-expressing transformants has allowed in situ detection of soluble carbohydrate uptake at various infection stages in $M$. graminicola. Monitoring uptake can be improved by engineering short-lived GFPs (Andersen et al. 1998) that make fluorescence measurement quantitative in order to more closely relate GFP promoter repression to decreased fluorescence. Quantitative measurement may allow 
characterization of cultivar resistance on the basis of apoplastic carbohydrate availability for fungal uptake. This study indicates that there is a conservation of the $a c u-3$ and $g p d A$ promoter function between $M$. graminicola, whose molecular biology is poorly characterized, and model organisms such as
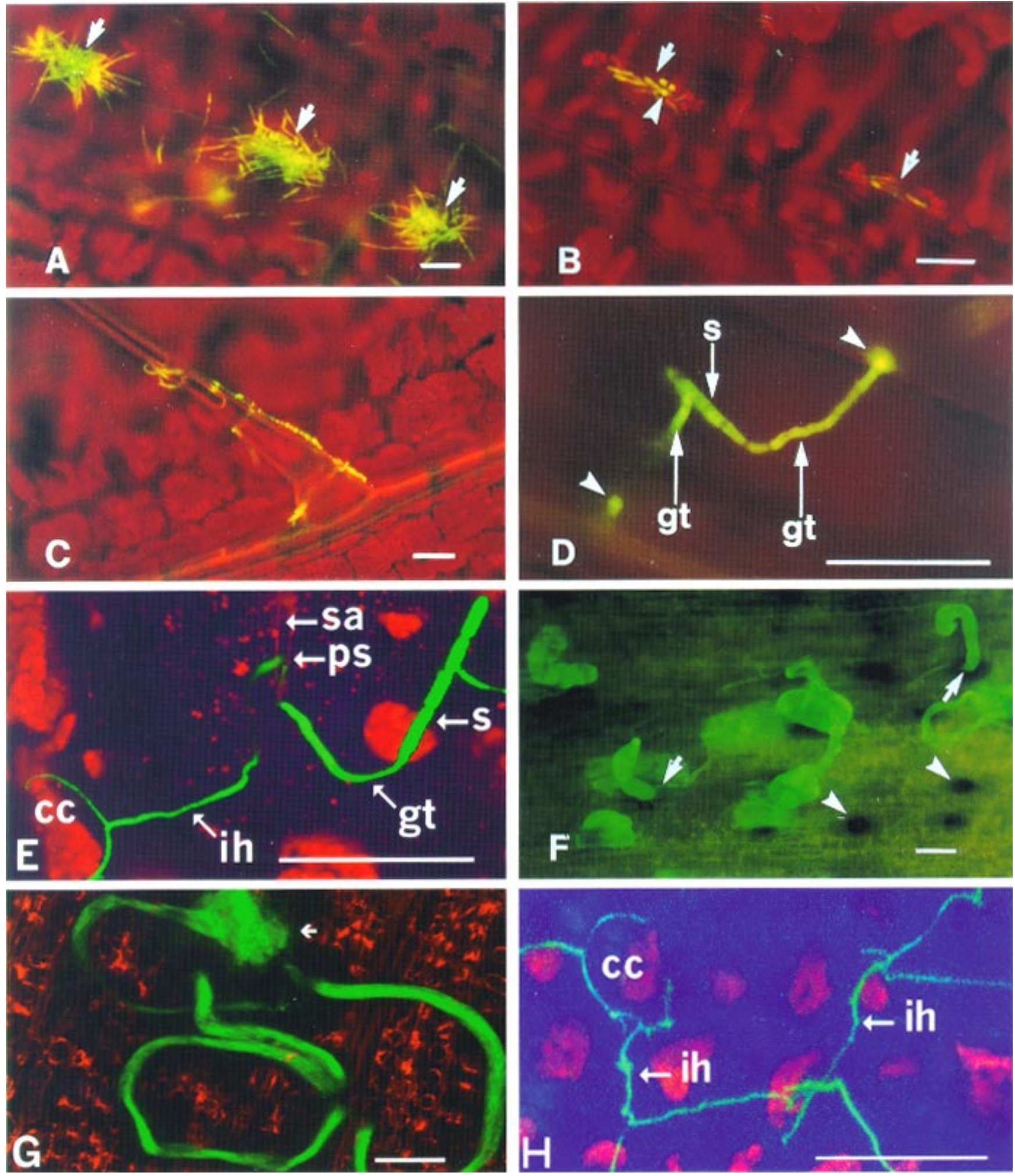

A. nidulans and $N$. crassa. The novel characteristics of GFP provide new opportunities to use the well-characterized promoters of $A$. nidulans and $N$. crassa in $M$. graminicola to monitor the pathogenic development and physiological status of fungal cells during infection.
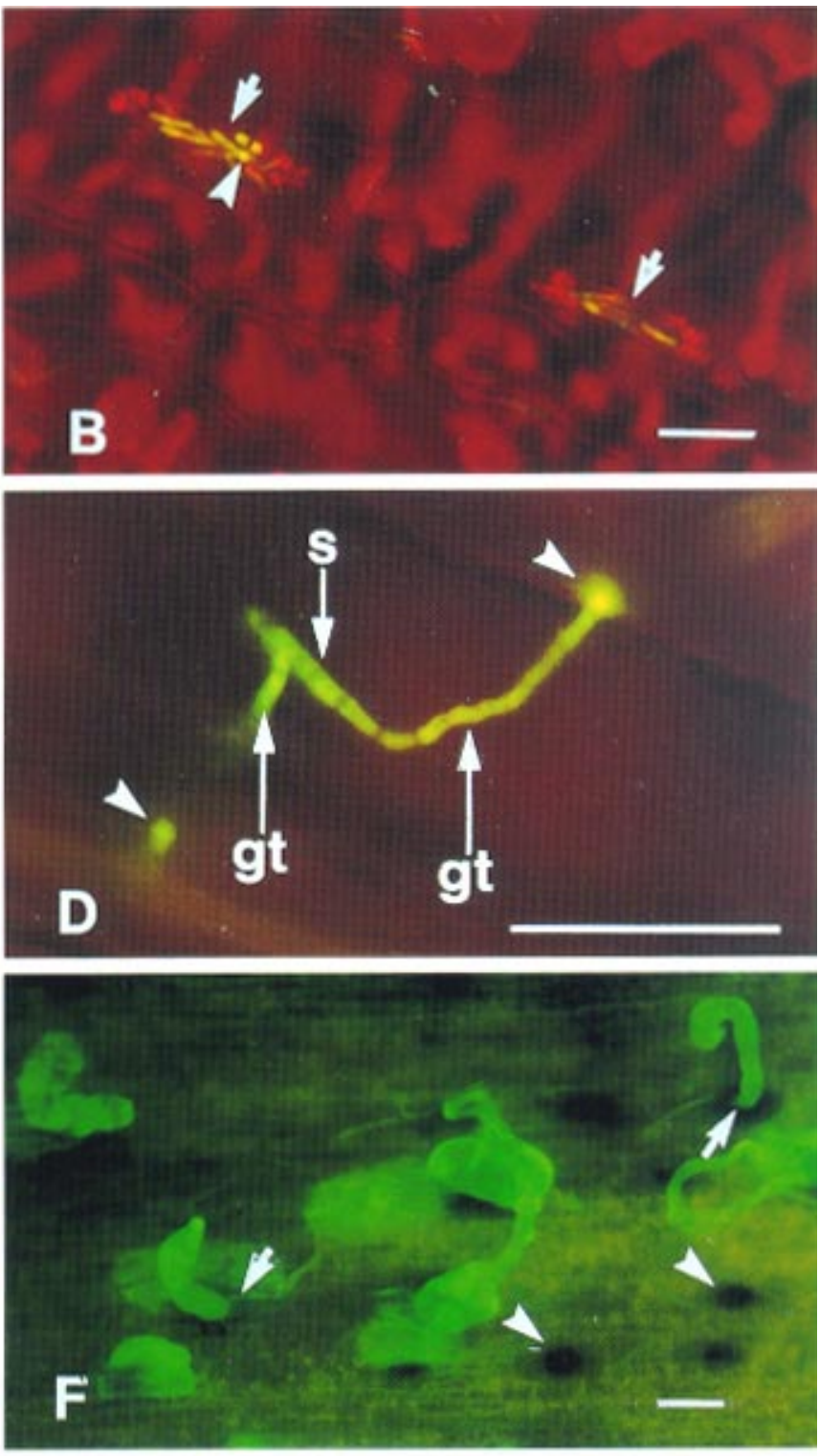


\section{MATERIALS AND METHODS}

\section{Strains, culture conditions, and constructs.}

Wild-type M. graminicola strain ST16 and growth conditions are described in Payne et al. (1998). ST16 was cotransformed with equimolar quantities of pAN7-1 (Punt et al. 1987) that bears the hygromycin $B$ resistance gene and either pICL-GFP or pGPD-GFP. pICL-GFP contains a 2.5-kb PstINcoI fragment of the $a c u-3$ promoter (Bibbins et al. 1998) upstream of NcoI-ClaI-digested SGFP-S65T-nos (Sheen et al. 1995) cloned into PstI-ClaI-digested pBluescript-KS (Stratagene, La Jolla, CA, U.S.A.). pGPD-GFP (received from M.H. Lebrun, Aventis Crop Sciences, Lyon, France) contains the 717-bp fragment of SGFP-S65T cloned downstream of the gpdA promoter from A. nidulans in NcoI-BamHI-digested pAN52-1 (Punt et al. 1987).

\section{Fluorometry.}

GFP expression in $M$. graminicola cells was monitored in microtiter plates with a LS 50B spectrofluorometer (Perkin Elmer, Beaconsfield, U.K.) set on 485-nm excitation and 520$\mathrm{nm}$ emission wavelengths with a $10-\mathrm{nm}$ slit width in both cases. An emission filter was set at $515 \mathrm{~nm}$. Assays were carried out in duplicate, at $18^{\circ} \mathrm{C}$ into darkness. Spores from liquid cultures were harvested by centrifugation, washed extensively, and resuspended in water. Spores were starved for $12 \mathrm{~h}$ on a rotary shaker, and suspensions were then adjusted to an optical density at $600 \mathrm{~nm}$ of 0.6 (approximately $10^{7}$ spores per milliliter) in water and $100 \mu \mathrm{l}$ was added to each microtiter plate well. Carbon sources were added to the spore suspensions at a final concentration of $50 \mathrm{mM}$. Water controls (without spores) were performed for each carbon source, and weak carbon source fluorescence was subtracted from fluorescence values measured in the corresponding cultures. Fluorescence of the untransformed strain ST16 was monitored as an additional control.

\section{Inoculation of plants.}

Single-spore-derived transformants were grown for 5 days at $18^{\circ} \mathrm{C}$ on potato dextrose agar medium (Oxoid, Basingstoke,

\section{$\leftarrow$}

Fig. 5. Epifluorescence microscope (EFM) and confocal laser scanning microscope (CLSM) images of Mycosphaerella graminicola infection structures in wheat leaves. A and B, Adhesion of spores on stomatal apertures. A, acu-3-regulated ICL-GFP4 transformant, 9 days postinoculation (dpi); B, gpdA-regulated GPD-GFP6 transformant, 3 dpi; EFM images. Arrows point to stomata; arrowhead in B points to a bright structure corresponding to a penetration site. C, Germ tubes wrapped around a trichome (ICL-GFP4 transformant, EFM image, 8 dpi). D, Germinated spore (S) with two germ tubes (GT) (ICL-GFP4 transformant, EFM image, $7 \mathrm{dpi}$ ). Each germ tube ends with a bright penetration structure (arrowheads) above epidermal cell junctions. One of the germ tubes is out of focus. E, Spore (S) with a germ tube (GT) and an infection hypha (IH) penetrating through a stomatal aperture (SA). The infection hypha grows in the mesophyll below the penetration site (PS) and wraps around a mesophyll cell with red-fluorescing chlorophyll (CC) (GPD-GFP6 transformant, projected CLSM image, 6 dpi). F and G, ICL-GFP4 transformant pycnidia (arrows) oozing green fluorescent cirrhi (F, EFM image; G, projected CLSM image; 24 dpi). Arrowheads in $\mathbf{F}$ point to immature pycnidia without cirrhi. Yellow fluorescence associated with the necrosed leaf surface represents autofluorescence. H, Infection hyphae (IH) growing in the mesophyll and wrapping around a cell with red-fluorescing chlorophyll (CC) (gpdA-regulated GPD-GFPB3 transformant, projected CLSM image, 11 dpi). Scale bars $=50 \mu \mathrm{m}$, except for $\mathbf{F}$ and $\mathbf{G}$, which $=500 \mu \mathrm{m}$.
U.K.) that contained $100 \mu \mathrm{g}$ of hygromycin B (Calbiochem, La Jolla, CA, U.S.A.) per milliliter. Spores were harvested in $0.01 \%$ (vol/vol) Tween 20 and suspensions adjusted to $10^{7}$ spores per milliliter. Primary leaves of 10-day-old seedlings of the susceptible wheat cultivar Riband (PBI-Cambridge, Cambridge, U.K.) were grown in a controlled-environment cabinet set at $18^{\circ} \mathrm{C}$ in a $16-\mathrm{h}$ day with $50 \mathrm{~W}$ per square meter of light and inoculated with a single $10-\mu \mathrm{l}$ droplet of spore suspension. Inoculated plants were left to stand for $30 \mathrm{~min}$ at room temperature and then maintained in a controlled-environment cabinet, as described above, in $100 \%$ humidity. Four replicate leaves per transformant were sampled daily for microscopic observation. Five and two leaves per transformant also were sampled for protein and DNA extraction, respectively, in a separate experiment.

\section{Western blot and PCR analysis.}

Total protein extracts were obtained through grinding in liquid nitrogen approximately $10^{7}$ spores from in vitro cultures starved in water for $12 \mathrm{~h}$ or five infected leaf segments, and resuspending in $20 \mathrm{mM}$ Tris-HCL (pH 7.4), $200 \mathrm{mM} \mathrm{NaCl}, 2$ $\mathrm{mM}$ dithiothreitol, and Complete protease inhibitors (Boehringer, Mannheim, Germany). Infected leaf segments were thoroughly washed before grinding to remove excess inoculum. Protein was quantified with Bio-Rad protein assay reagent (Hemel Hempstead, U.K.), separated by $10 \%$ (wt/vol) sodium dodecyl sulfate-polyacrylamide gel electrophoresis (Laemmli 1970), and transferred to Hybond $\mathrm{P}$ membrane (Amersham Pharmacia Biotech, Uppsala, Sweden) by semidry blotting (Bio-Rad). GFP polypeptides were detected with an anti-GFP monoclonal antibody (Clontech, Basingstoke, U.K.). The monoclonal antibody UB7 (Mitchell et al. 1997) was used as a control. UB7 binds specifically to constitutively expressed fungal glycoproteins restricted to a subset of the fungi and does not bind to plant glycoproteins. Membranes were incubated with antimouse-conjugated horse radish peroxidase and, finally, with luminol (Amersham Pharmacia Biotech) before autoradiography. PCR quantification of $M$. graminicola DNA in infected leaves was carried out as described in Fraaije et al. (1999). A fragment of an M. graminicola beta-tubulin gene was amplified from infected-leaf total DNA with specific primers, and the PCR-amplified product was quantified by fluorometry with PicoGreen dye (Molecular Probes, Leiden, The Netherlands). M. graminicola DNA in infected leaves was then quantified with the use of a calibration curve generated by PCR amplification of healthy wheat leaf DNA mixed with different amounts of genomic $M$. graminicola DNA. Two infected leaf segments were washed and processed for each sample. Replicate fluorometric measurements were performed.

\section{Microscopy.}

The area of the leaf around the inoculation site was excised and gently washed in $0.01 \%$ ( $\mathrm{vol} / \mathrm{vol}$ ) Tween 20 to remove excess inoculum. Leaf fragments were mounted in glycerol and inspected with a Zeiss Axiophot epifluorescence microscope (Welwyn Garden City, U.K.). GFP was visualized with a mercury lamp and a fluorescein isothiocyanate filter set with a BP450 to BP490 excitation filter (Carl Zeiss Ltd.), 510-nm dichroic mirror, and a LP590 emission filter set (Carl Zeiss Ltd.). Confocal microscopy was performed with a Leica 

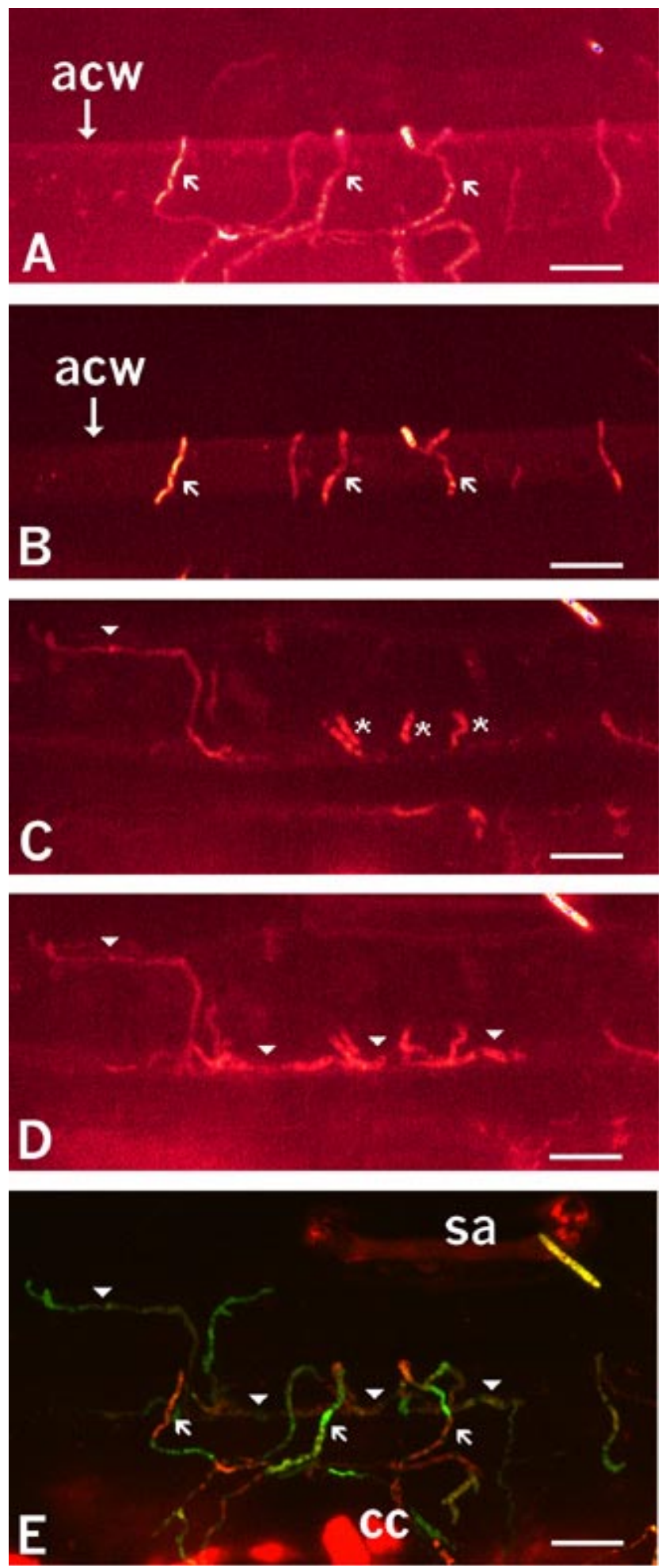

Fig. 6. Direct penetration of $g p d A$-regulated GPD-GFP6 transformant hyphae at epidermal cell junction (11 days postinoculation). Confocal laser scanning microscope (CLSM) created $3 \mu \mathrm{m}$ optical sections collected in the plane of the leaf through $40 \mu \mathrm{m}$ of infected leaf tissue. A to D, Merged projections of three to five optical sections from the leaf surface A, to the mesophyll $\mathbf{D}$. Arrows point to hyphae located on the leaf surface at the upper junction of two epidermal cells; arrowheads point to a mycelial strand forming at the lower junction, just below the epidermis. Asterisks in $\mathbf{C}$ indicate hyphae penetrating along the anticlinal cell wall (ACW). E, Merged projection of the 16 CLSM optical sections. $\mathrm{CC}=$ cell with red-fluorescing chlorophyll in the mesophyll; $\mathrm{SA}=$ stomatal aperture. Scale bars $=50 \mu \mathrm{m}$.
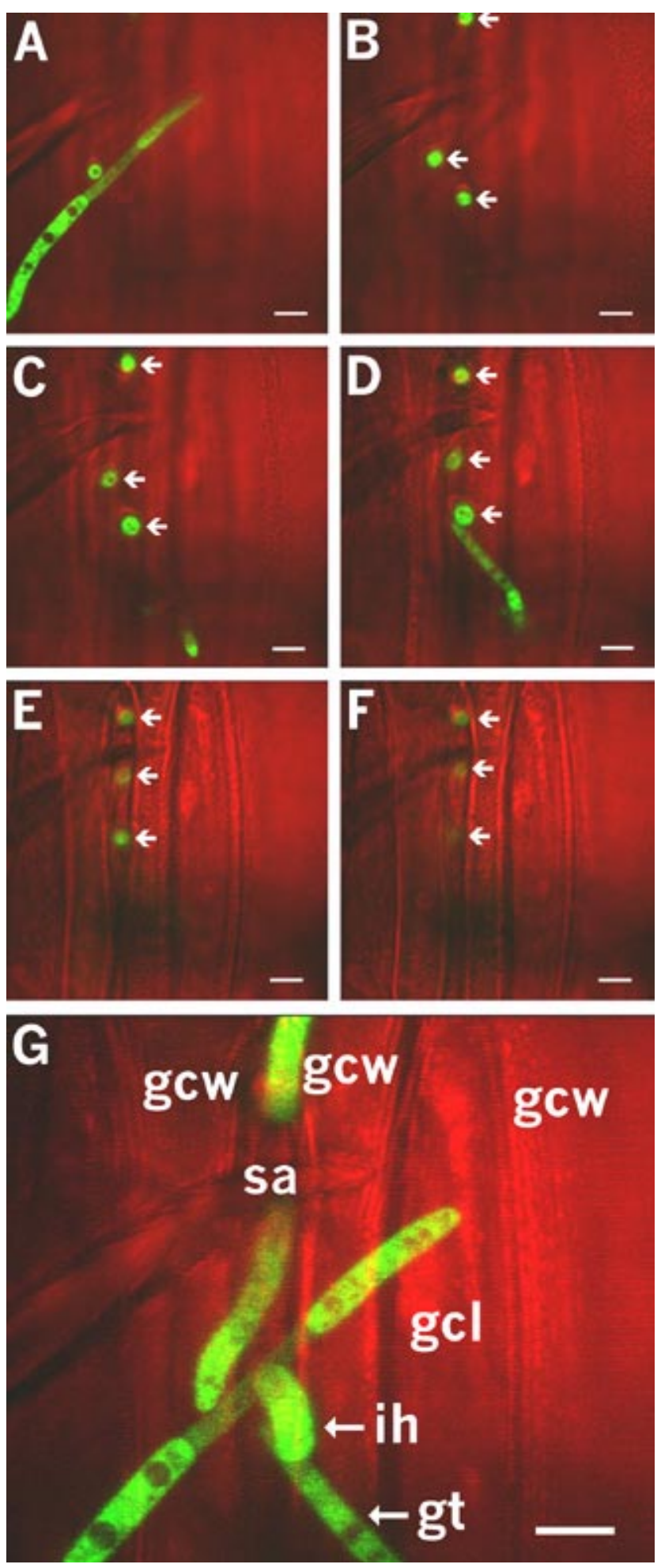

Fig. 7. $а с u-3$ promoter repression inhibits green fluorescent protein synthesis in $a c u$-3-regulated ICL-GFP4 transformant during penetration through stomatal aperture (11 days postinoculation). Confocal laser scanning microscope (CLSM) created $3 \mu \mathrm{m}$ optical sections collected in the plane of the leaf through $60 \mu \mathrm{m}$ of infected leaf tissue. A to $\mathbf{F}$, Gallery of six optical sections every $9 \mu \mathrm{m}$ from the leaf surface $\mathbf{A}$, to the substomatal chamber $\mathbf{F}$. Note the decrease of fluorescence in the three penetrating hyphae (arrows). G, Merged projection of the 20 CLSM optical sections. GCW = guard cell wall; $\mathrm{GCL}=$ guard cell lumen; $\mathrm{SA}=$ stomatal aperture; GT = spore germ tube; and $\mathrm{IH}=$ infection hyphae . Scale bar $=10 \mu \mathrm{m}$. 
TCS-NT scanning laser confocal instrument that included an argon-krypton UV laser (Leica Lasertechnik, Heidelberg, Germany).

\section{ACKNOWLEDGMENTS}

We thank M. A. Jepson (University of Bristol) and R. Primault (University of Rennes) for technical assistance in confocal laser scanning microscopy, and P. Bowyer and R. O'Connell of the Long Ashton Research Station, U.K., for material contributions, ideas, and discussions. This research was supported by funds from Rhône-Poulenc Agro (now Aventis), Zeneca Sopra, BBSRC, and the French Agrochemical Industry represented by UIPP. This work was carried out under license PHL 19/2176/11/1996, issued by the U.K. Ministry of Agriculture, Fisheries and Food, allowing us to keep genetically modified plant pests.

\section{LITERATURE CITED}

Andersen, J. B., Sternberg, C., Poulsen, L. K., Bjorn, S. P., Givskov, M., and Molin, S. 1998. New unstable variants of green fluorescent protein for studies of transient gene expression in bacteria. Appl. Environ. Microbiol. 64:2240-2246.

Basse, C. W., Stumpferl, S., and Kahmann, R. 2000. Characterization of a Ustilago maydis gene specifically induced during the biotrophic phase: Evidence for negative as well as positive regulation. Mol. Cell. Biol. 20:329-339.

Bibbins, M., Sheffield, P. J., Gainey, L. D. S., Mizote, T., and Connerton, I. F. 1998. Promoter analysis of the acetate-inducible isocitrate lyase gene (acu-3) from Neurospora crassa. Biochim. Biophys. Acta 1442:320-325.

Bowyer, P., Ramon De Lucas, J., and Turner, G. 1994. Regulation of the expression of the isocitrate lyase gene (acuD) of Aspergillus nidulans. Mol. Gen. Genet. 242:484-489.

Clark, J. S. C., and Spencer-Phillips, P. T. N. 1993. Accumulation of photoassimilate by Peronospora viciae (Berk.) Casp. and leaves of Pisum sativum L.: Evidence for nutrient uptake via intercellular hyphae. New Phytol. 124:107-119.

Cohen, L., and Eyal, Z. 1993. The histology of processes associated with the infection of resistant and susceptible wheat cultivars with Septoria tritici. Plant Pathol. 42:737-743.

Coleman, M., Henricot, B., Arnau, J., and Oliver, R. P. 1997. Starvationinduced genes of the tomato pathogen Cladosporium fulvum are also induced during growth in planta. Mol. Plant-Microbe Interact. 10:1106-1109.

Derridj, S. 1996. Nutrients on the leaf surface. Pages 25-42 in: Aerial Plant Surface Microbiology. C. E. Morris, P. C. Nicot, and C. Nguyen-The, eds. Plenum Press, New York.

Fraaije, B. A., Lovell, D. J., Rohel, E. A., and Hollomon, D. W. 1999. Rapid detection and diagnosis of Septoria tritici epidemics in wheat using a polymerase chain reaction/picogreen assay. J. Appl. Microbiol. 86:701-708.

Hardham, A. R. 1992. Cell biology of pathogenesis. Annu. Rev. Plant
Physiol. Plant Mol. Biol. 43:491-526.

Heath, M. C., and Skalamera, D. 1997. Cellular interactions between plants and biotrophic fungal parasites. Adv. Bot. Res. 24:195-225.

Kema, G. H. J., Yu, D., Rijkenberg, F. H. J., Shaw, M. W., and Baayen, R. P. 1996. Histology of the pathogenesis of Mycosphaerella graminicola in wheat. Phytopathology 86:777-786.

Kershaw, M. J., Wakely, G., and Talbot, N. J. 1998. Complementation of the Mpg 1 mutant phenotype in Magnaporthe grisea reveals functional relationships between fungal hydrophobins. EMBO J. 17:3838-3849.

Laemmli, U. K. 1970. Cleavage of structural proteins during the assembly of the head of bacteriophage T4. Nature 227:680-685.

Manners, J. M., and Gay, J. L. 1982. Transport, translocation and metabolism of ${ }^{14} \mathrm{C}$-photosynthates at the host-parasite interface of Pisum sativum and Erysiphe pisi. New Phytol. 91:221-244.

Maor, R., Puyesky, M., Horwitz, B. A., and Sharon, A. 1998. Use of green fluorescent protein (GFP) for studying development and fungalplant interaction in Cochliobolus heterostrophus. Mycol. Res. 102:491-496

McCullough, W., and Roberts, C. F. 1980. Genetic regulation of isocitrate lyase activity in Aspergillus nidulans. J. Gen. Microbiol. 120:67-84.

Mitchell, A. J., Hutchinson, K. A., Pain, N. A., Callow, J. A., and Green, J. R. 1997. A monoclonal antibody that recognizes a carbohydrate epitope on $\mathrm{N}$-linked glycoproteins restricted to a subset of chitin-rich fungi. Mycol. Res. 101:73-79.

Parbery, D. G. 1996. Trophism and the ecology of fungi associated with plants. Biol. Rev. 71:473-527.

Payne, A. C., Grosjean-Cournoyer, M. C., and Hollomon, D. W. 1998. Transformation of the phytopathogen Mycosphaerella graminicola to carbendazim and hygromycin B resistance. Curr. Genet. 34:100-104.

Punt, P. J., Oliver, R. P., Dingemanse, M. A., Pouwels, P. H., and Van den Hondel, C. A. M. J. J. 1987. Transformation of Aspergillus based on the hygromycin B resistance marker from Escherichia coli. Gene 56:117-124.

Punt, P. J., Dingemanse, M. A., Kuivenhoven, A., Soede, R. D. M., Pouwels, P. H., and den Hondel, C. A. M. J. J. 1990. Functional elements in the promoter region of the Aspergillus nidulans gpdA gene encoding glyceraldehyde-3-phosphate dehydrogenase. Gene 93:101-109.

Royle, D. J., Shaw, M. W., and Cook, R. J. 1986. Patterns of development of Septoria nodorum and S. tritici in some winter wheat crops in Western Europe, 1981-83. Plant Pathol. 35:466-476.

Sheen, J., Hwang, S., Niwa, Y., Kobayashi, H., and Galbraith, D. W. 1995. Green fluorescent protein as a new vital marker in plant cells. Plant J. 8:777-784.

Spellig, T., Bottin, A., and Kahmann, R. 1996. Green fluorescent protein (GFP) as a new vital marker in the phytopathogenic fungus Ustilago maydis. Mol. Gen. Genet. 252:503-509.

Talbot, N. J., McCafferty, H. R. K., Ma, M., Moore, K., and Hamer, J. E. 1997. Nitrogen starvation in the rice blast fungus Magnaporthe grisea may act as an environmental cue for disease symptom expression. Physiol. Mol. Plant Pathol. 50:179-195.

Tetlow, I. J., and Farrar, J. F. 1993. Apoplastic sugar concentration and $\mathrm{pH}$ in barley leaves infected with brown rust. J. Exp. Bot. 44:929-936. 